\title{
Views of Mental Health Professionals on Positive Changes in Service Practices and Staff-User Relationships After One Year of Covid-19 Pandemic in Italy
}

\author{
Lorenza Magliano $\mathbb{D}$ - Tommaso Bonavigo $\mathbb{D}$ - Claudia Battiston • \\ Alessandra Oretti - Roberta Accardo - Gabriella D'Ambrosi - Gaetana Affuso (i) \\ Elisabetta Pascolo-Fabrici (i)
}

Received: 7 September 2021 / Accepted: 4 January 2022 / Published online: 20 January 2022

(C) The Author(s) 2022

\begin{abstract}
This study explored views of mental health services (MHS) professionals regarding positive changes in service practices and organizations, and staff-user relationships after one year of COVID19 in Italy. Professionals from a community-oriented MHS completed online the Questionnaire on MHS Transformations during the COVID-19 pandemic, a 30-item tool developed by a participatory approach and validated. Of the 184 participants, $91.8 \%$ felt it was "true/definitely true" that during the pandemic they had informed users on procedures to reduce contagion risks, and $82.1 \%$ stated that they had increased telephone contact with users. Sixty-nine percent of professionals reported that staff revised treatment plans according to new needs of care and $78.6 \%$ stated that they had been able to mediate between user needs and safe working procedures.
\end{abstract}

L. Magliano $(\bowtie) \cdot$ G. Affuso

Department of Psychology, University of Campania

"Luigi Vanvitelli", Viale Ellittico 31, 81100 Caserta, Italy

e-mail: lorenza.magliano@unicampania.it

T. Bonavigo $\cdot$ C. Battiston - A. Oretti ·

R. Accardo · G. D'Ambrosi · E. Pascolo-Fabrici

Department of Mental Health, Giuliano Isontina

University Health Authority (Azienda Sanitaria

Universitaria Giuliano Isontina - ASUGI), Trieste, Italy

E. Pascolo-Fabrici

Clinical Department of Medical, Surgical and Health

Sciences, University of Trieste, 34149 Trieste, Italy
Moreover, $79.4 \%$ of respondents stated that they had rediscovered the importance of gestures and habits, and $65 \%$ that they had gained strength among colleagues to face fear. Fifty-four percent of participants admitted that they had discovered unexpected personal resources in users. Overall, 59.6\% of participants stated that they found some positives in the COVID-19 experience. Perceived positive changes was greater among professionals from community facilities vs. those from hospital and residential facilities. In community-oriented MHS, the pandemic offered an opportunity to change practices and rethink the meaning of relationships between people. This data may be useful in generating a more balanced understanding of COVID-19's impact on MHS and for MHS planning in the pandemic era.

Keywords COVID-19 $\cdot$ Mental health staff $\cdot$ Mental health services $\cdot$ Service users $\cdot$ Staff views

\section{Introduction}

Since the early phase of COVID-19 pandemic, research has shown an increase of mental health problems in the general population [23, 30] and negative effects on mental health services (MHS) $[12,30]$, particularly in the reduction of hospital and community activities, and the closure of residential 
facilities $[2,5,26]$. In persons with mental disorders, clinical worsening, increased social isolation [9], and difficulties in accessing care were reported [26]. Among the staff, stress and burnout were indicated [22], mainly related to abrupt work changes, fear of contagion, and difficulty in ensuring acceptable levels of care to persons with severe mental disorders [15].

While negative effects of COVID-19 pandemic on MHS have been largely described, its potential beneficial effects have been relatively unexplored. The preponderance of difficulty-focused studies $[4,9,15,26]$ may have led to an underestimation of the role those adaptive mechanisms may have exerted on MHS staff, positively influencing relationships and practices. Available data revealed that sometimes the COVID-19 pandemic has led to increased staff collaboration, reduced bureaucracy, and greater flexibility in healthcare $[1,11,15]$. Remote work was useful to facilitate staff participation in meetings and to provide psychological support and clinical assessments to users $[4,15,26]$. Staff perception of the pandemic as leading something useful was also reported [4]. In users with severe mental disorders, the widespread reduction in social relationships has been found to be associated with reduced marginalization and increased empathy toward them [9]. The focus on the pandemic seemed to distract some users from their mental condition, apparently leading to symptom relief [26] and a greater community involvement [9]. Available studies were often conducted using qualitative methodologies, which are difficult to adopt in routine settings, or through poorly validated tools. Moreover, most studies were conducted at the beginning of the pandemic, when coping mechanisms were centered on initial emotional reactions, but these were later replaced by problem solving strategies [17]. It is likely that the persistence of COVID-19 pandemic has led mental health professionals to develop new organizational and intervention approaches, and to give new values to their work and the relationships with users and their families. Knowledge of this data may be useful in generating a more balanced understanding of COVID-19 pandemic's impact on MHS and for mental health policy planning in the pandemic era [10].

During the first year of the COVID-19 pandemic, Italy was one of the most affected European countries, with 2,800,000 infected people and 95,000 fatalities at one year $[14,21]$. During the first lockdown (from
March 9 to May 18, 2020), MHS activities dropped by $30 \%$ overall, while voluntary and compulsory hospital admissions dropped by $50 \%$ and $70 \%$, respectively $[2,24]$. In MHS closely aligned to a communityoriented approach, outpatients services continued to operate normally during the emergency, while hospital services decreased their activities [3]. As of summer 2020, most clinical and rehabilitation activities gradually resumed at the pre-COVID-19 levels, including collaboration of the third sector and user and family associations [7].

This study explored views of MHS professionals regarding the beneficial changes occurred in service practices and organizations, and in staff-user relationships during the first year of the COVID-19 pandemic in Italy. The research was conducted in the Trieste MHS, one of the MHS network with the longest experience of community care in Italy and internationally [20,28]. The study was carried out using an ad hoc questionnaire developed by a participatory approach and then validated. In particular, the study examined views of the MHS staff regarding the following issues:

(a) Acknowledgement of user capabilities

(b) Awareness and value of teamwork

(c) Flexibility and ability to reinvent the service

(d) Maintenance and introduction of best practices

(e) Acknowledgement of positive aspects in the pandemic experience.

With respect to the issues listed above, the study tested whether the perception of beneficial changes was greater in staff from community services vs. those from hospital and residential services.

\section{Materials and Methods}

\section{Study Design and Participants}

The research was conducted in the Trieste MHS from September to December 2020 (preliminary phase of instrument development) and from February to March 2021 (main phase of data collection). The Trieste MHS is managed by the Department of Mental Health of the Giuliano Isontina University Health Authority (Azienda Sanitaria Universitaria Giuliano Isontina ASUGI) and covers Trieste and the nearby territory of Gorizia (catchment area: 370,000 inhabitants). 
The eligible sample consisted of professionals from the Mental Health Department and the third sector working in synergy with the Department. Staff hired after March 2020 (first COVID-19 lockdown in Italy) were excluded from the study. The expected sample was 248 Mental Health Department staff and 174 third sector staff, respectively. Potential participants were invited to complete online an anonymous questionnaire on their views regarding the positive changes occurred in the MHS during the pandemic. The questionnaire was specifically developed for the purposes of the study by using a participatory approach (see assessment instrument section).

The study was coordinated by the Department of Psychology of the University of Campania "Luigi Vanvitelli", Caserta, Italy and conducted in collaboration with the Department of Mental Health of the Giuliano Isontina University Health Authority (ASUGI), Trieste, Italy. Study protocol was approved by the Ethics Committee of the Department of Psychology of the University of Campania "Luigi Vanvitelli", Caserta, Italy (authorization n. 1 of $2 / 2$ / 2021) and acknowledged by the Office of Clinical and Epidemiological Studies, SC Research and Innovation, ASUGI, Trieste, Italy. The study was conducted in accordance with the Helsinki Declaration.

\section{Setting}

The Trieste MHS network adheres to a no-restraint system of care and operates according to "open door" and maximum accessibility principles (non-selection of demands) [19]. It includes community mental health centers, a general hospital psychiatric unit, and residential facilities. The community mental health centers are open $24 \mathrm{~h}$ a day, 7 days a week and cover most care needs, including crisis management, mental disorder prevention, and pharmacological and rehabilitative interventions. The general hospital psychiatry unit is a six-bed ward located in the General Hospital of Trieste and serving the entire catchment area of the Trieste MHS. This inpatients unit is dedicated to voluntary and compulsory admissions of persons with acute psychiatric symptoms. It is mainly used for night emergencies and the duration of admissions is short (a few days): people are transferred as soon as possible from the psychiatric unit of the general hospital to the reference mental health center, where there are additional beds for the community management of acute psychiatric conditions. Residential care is provided by supported housing facilities managed by the third sector in collaboration with the Mental Health Department. The Mental Health Department collaborates with many social cooperatives promoting recovery, social inclusion, and employment programs. Individuals are supported in accessing social opportunities and in pursuing individualized rehabilitative plans, developed using a health budget approach [8, 27]. The Trieste MHS network is listed by the WHO as one of the most innovative and well-established community mental health systems [28, 29].

\section{Data Collection}

The online data collection was conducted from February 15 through March 31, 2021. At the beginning of the data collection and twice during it, potential participants received an email from the employer inviting them to participate in an online study requesting their views regarding the transformations that occurred in the service during the first year of the COVID-19 pandemic. Those who accepted completed the Questionnaire on MHS Transformations during the COVID-19 pandemic-Staff version (QT-S). The research was also presented at the monthly team meeting by the Mental Health Department Director in March 2020. Participation was also solicited by word of mouth and WhatsApp by Mental Health Department coordinators and referents from cooperatives.

Participants completed the QT-S online using their personal devices (staff received a link to Google forms via invitation e-mails and WhatsApp messages). The possibility to stop the completion of QT-S and delete the answers already given was guaranteed by the online mode (simply close the Internet page without saving).

\section{Assessment Instrument}

The QT-S is a self-reported assessment instrument exploring staff views on potential positive changes occurred in MHS during the pandemic. The QT-S development took place from September to December 2020 by a workgroup including researchers, clinicians, and coordinators of the main health sectors involved in the study. Initially, workgroup members individually examined six video interventions by staff presented at 
a webinar on the effects of COVID-19 pandemic on the MHS network of Trieste and Gorizia, held in September 2020 [6]. Using an ad hoc form, each participant extrapolated the prevailing themes from the video-interventions and rephrased the speakers' statements as multiple-choice items. This process led to a preliminary list of 232 items that were individually scored by the participants for clarity/appropriateness on a 10-point scale,-ranging from 1 "not at all" to 10 "completely" — and for inclusion/exclusion in the questionnaire. Items with a clarity/appropriateness score $<7$ and/or suitable for inclusion by no more than $4 / 7$ participants were eliminated $(\mathrm{N}=160)$. The remaining 72 items were revised by the workgroup, and 25 redundant items were removed. The 47 items were re-evaluated for clarity/usefulness and inclusion/exclusion, and additional 17 items were excluded. The final 30 items were grouped on the following content basis: a) Acknowledgement of user capabilities (5 items); b) Awareness and value of teamwork (8 items); c) Flexibility and ability to reinvent the service (4 items); d) Maintenance and introduction of best practices (12 items); e) Acknowledgement of positive aspects in the pandemic experience ( 1 item). The rating scale included 6 levels, ranging from 1 "not really true" to 6 "really true." In addition to the 30 items there was: an initial section of study aims and informed consent to participate and publish data; two additional open-ended items on respondent views of the most positive and most negative effects of COVID-19 pandemic on MHS; and, a section on the respondent's main sociodemographic and professional characteristics.

\section{Statistical Analysis}

Descriptive statistics were computed based on QT-S 30 -items and the main socio-demographic and professional characteristics. Confirmatory Factorial Analysis was performed on the global sample to verify QT$S$ construct validity. Maximum likelihood estimation of the covariances was applied. Cronbach's $\alpha$ values were computed to explore content validity of the confirmed factors. Multivariate Analysis of Variance and Bonferroni's post-hoc were used to compare the mean scores of the five QT-S factors (dependent variables) with respect to main work settings (community mental health centres vs. social cooperatives vs residential facilities vs. general hospital psychiatric unit-independent variable). Statistical significance level was set at $p<0.05$. Confirmatory Factorial Analysis was performed using the LISREL 8 Program [16]. Other tests were performed using the SPSS package, version 21 [13].

\section{Results}

A total of 184 professionals completed the online questionnaire (participation rate: 43.6\%). Participants had a mean age of $46.3 \pm 10.5(\mathrm{SD})$ years and most of them were females $(61.4 \%)$, and highly educated (68.5\%). Participants' professional roles were as follows: psychiatrist 9.2\%; psychologist 6.0\%; nurse $31.0 \%$; health care assistant $4.9 \%$; educator/rehabilitator $23.8 \%$; social cooperatives worker $16.3 \%$; social worker $1.6 \%$; administrative staff $3.3 \%$; other/not specified: $3.7 \%$. Participants worked in the mental health field for $13.8 \pm 9.5$ years on average. Of the 184 participating professionals, $48.4 \%$ worked in community mental health centers, $31.0 \%$ in social cooperatives, $7.6 \%$ in the general hospital psychiatric unit, and $6.5 \%$ worked in residential facilities (missing data $6.5 \%)$.

Ninety-two percent of participants felt it was "true/ definitely true" (scores 5 and 6) that during the pandemic they had informed users on procedures to reduce individual risk of contagion, and $82.6 \%$ stated that they had taken greater care in the cleanliness of the environments (Table 1). Eighty-two percent stated that they had increased telephone contact with users, and $69.3 \%$ reported that staff revised individual treatment plans according to users' new needs of care. Moreover, $58.6 \%$ of respondents stated that they had paid greater attention to users' physical health, and $66.2 \%$ indicated that they had managed people in crisis as much as possible at home. Seventy-nine percent of staff learned to use digital technologies to work with public and private social institutions. Seventy-nine percent stated that the staff had been able to mediate between user needs and safe working procedures and $57.1 \%$ indicated that they had become more flexible regarding working alongside people during the pandemic. Moreover, $79.4 \%$ of respondents stated that the team had rediscovered the importance of gestures and habits, and $65.0 \%$ that they had gained strength among colleagues to face fear. Fifty-four percent of participants admitted that they had 
Table 1 Views of MHS staff on positive changes during the first year of the COVID-19 pandemic $(\mathrm{N}=184)$

QT-S items

Not really true Really true

\begin{tabular}{|c|c|c|c|c|c|c|c|c|c|c|c|}
\hline 1 & & 2 & & 3 & & 4 & & 5 & & 6 & \\
\hline $\mathrm{N}$ & $\%$ & $\mathrm{~N}$ & $\%$ & $\mathrm{~N}$ & $\%$ & $\mathrm{~N}$ & $\%$ & $\mathrm{~N}$ & $\%$ & $\mathrm{~N}$ & $\%$ \\
\hline
\end{tabular}

\section{Acknowledgement of user capabilities}

*, people with severe mental disorder demonstrated good adaptive skills

*, I discovered personal resources in users that I did not believe they had

*, users organized themselves into peer support groups

$\begin{array}{lllllllllll}3 & 1.6 & 25 & 13.7 & 41 & 22.4 & 49 & 26.8 & 57 & 31.1 & 8\end{array}$

4.4

*, users showed that they were able to self-organize and find new solutions

*, I realized that there were users who know how to use digital technologies better than I did

$\begin{array}{llllllllllll}7 & 3.8 & 9 & 4.9 & 21 & 11.5 & 46 & 25.3 & 64 & 35.2 & 35 & 19.2\end{array}$

$\begin{array}{llllllllllll}34 & 19.5 & 43 & 24.7 & 45 & 25.9 & 29 & 16.7 & 14 & 8.0 & 9 & 5.2\end{array}$

$\begin{array}{llllllllllll}12 & 6.7 & 23 & 12.8 & 33 & 18.4 & 57 & 31.8 & 41 & 22.9 & 13 & 7.3\end{array}$

$\begin{array}{llllllllllll}29 & 16.4 & 27 & 15.3 & 24 & 13.6 & 36 & 20.3 & 30 & 16.9 & 31 & 17.5\end{array}$

Awareness and value of teamwork

*, we realized the importance of simple gestures like drinking coffee together, shaking hands, hugging each other

*, there was more sharing of responsibilities within the team

$\begin{array}{llllllllllll}6 & 3.3 & 6 & 3.3 & 10 & 5.4 & 16 & 8.7 & 43 & 23.4 & 103 & 56.0\end{array}$

*, more centrality was given to the meetings and to dialogue with the other person

*, I had more time to think about my work

*, we colleagues strengthened each other to face the fear

$\begin{array}{llllllllllll}15 & 8.2 & 22 & 12.1 & 31 & 17.0 & 37 & 20.3 & 46 & 25.3 & 31 & 17.0\end{array}$

, we colleagues strengthened each other to face the fear

*, the sense of being part of a team strengthened

$\begin{array}{lllllllllll}7 & 3.8 & 14 & 7.7 & 20 & 10.9 & 23 & 12.6 & 67 & 36.6 & 52\end{array}$

28.4

*, service meetings were an opportunity for group reflection on work practices

*, the guidelines of the Local Health Authority on how to $\quad \begin{array}{llllllllllll}26 & 14.3 & 28 & 15.4 & 40 & 22.0 & 43 & 23.6 & 33 & 18.1 & 12 & 6.6\end{array}$ work safely made us feel more reassured

\section{Flexibility and ability to reinvent the service}

*, we became more flexible toward remaining close to users

*, we reinvented our way of working in line with $\begin{array}{lllllllllll}16 & 8.8 & 19 & 10.5 & 26 & 14.4 & 55 & 30.4 & 42 & 23.2 & 23\end{array}$ government mandates

*, we were able to make organizational/operational changes very quickly

*, we mediated between user demands and the procedures needed to work safely

\section{Maintenance and introduction of best practices}

*, we increased phone contact with users

*, we took more better care maintaining cleanliness in the work environment

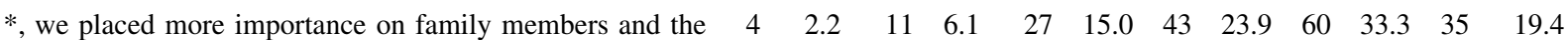
close relationships of users

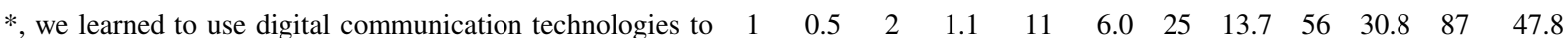
work with other public institutions and the third sector

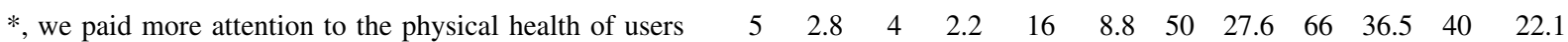

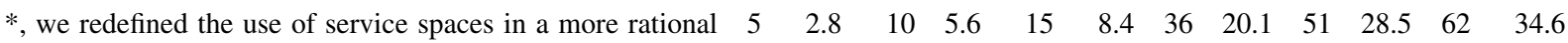
way

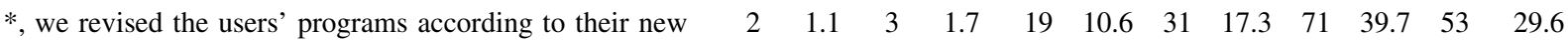
needs 
Table 1 continued

\begin{tabular}{|c|c|c|c|c|c|c|c|c|c|c|c|c|}
\hline \multirow[t]{3}{*}{ QT-S items } & \multicolumn{12}{|c|}{ Not really true Really true } \\
\hline & \multicolumn{2}{|l|}{1} & \multicolumn{2}{|l|}{2} & \multicolumn{2}{|l|}{3} & \multicolumn{2}{|l|}{4} & \multicolumn{2}{|l|}{5} & \multicolumn{2}{|l|}{6} \\
\hline & $\mathrm{N}$ & $\%$ & $\mathrm{~N}$ & $\%$ & $\mathrm{~N}$ & $\%$ & $\mathrm{~N}$ & $\%$ & $\mathrm{~N}$ & $\%$ & $\mathrm{~N}$ & $\%$ \\
\hline $\begin{array}{l}\text { *, learned to use the } \mathrm{PC} \text { and digital technologies better (e.g., } \\
\text { video calling and conferencing platforms) }\end{array}$ & 10 & 5.5 & 12 & 6.6 & 15 & 8.2 & 41 & 22.5 & 44 & 24.2 & 60 & 33.0 \\
\hline $\begin{array}{l}\text { *, the CMHC remained the key point of referral for people } \\
\text { with a fragile/absent family network }\end{array}$ & 9 & 5.2 & 11 & 6.4 & 13 & 7.5 & 27 & 15.6 & 47 & 27.2 & 66 & 38.2 \\
\hline $\begin{array}{l}\text { *, during hospitalization we guaranteed the contact of users } \\
\text { with their families }\end{array}$ & 2 & 1.2 & 11 & 6.7 & 15 & 9.1 & 29 & 17.7 & 57 & 34.8 & 50 & 30.5 \\
\hline *, we managed people in crisis as much as possible at home & 4 & 2.3 & 5 & 2.9 & 17 & 9.9 & 32 & 18.6 & 57 & 33.1 & 57 & 33.1 \\
\hline $\begin{array}{l}\text { *, we informed users about the pandemic and how to reduce } \\
\text { individual risk of infection }\end{array}$ & 0 & 0 & 1 & 0.5 & 5 & 2.7 & 9 & 4.9 & 62 & 34.1 & 105 & 57.7 \\
\hline
\end{tabular}

\section{Acknowledgement of positive aspects in the pandemic experience}

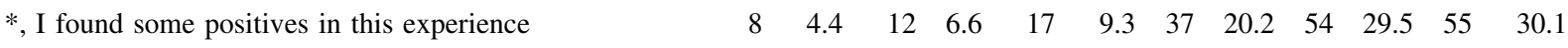

*During the pandemic

discovered personal resources in many users that they had not expected, and $35.5 \%$ acknowledged that persons with severe mental disorders had shown good adaptive skills in the pandemic. Overall, $59.6 \%$ of participants stated that they found some positives in the COVID-19 pandemic experience.

Confirmatory Factorial Analysis performed on the 30 QT-S items, confirmed the five-factor structure. The final model fit the data well, $\chi^{2}(396)=900.24$, $p<0.001$; non-normed fit index $[\mathrm{NNFI}]=0.90$; comparative fit index $[\mathrm{CFI}]=0.91$; root mean square error of approximation [RMSEA] $=0.087,90 \%$ C.I. $(0.080 ; 0.095)$; standardized root mean square residual [SRMR $]=0.086$. All factor loadings were significant at the $p<0.001$ level. Cronbach's $\alpha$ values ranged from 0.68 to 0.83 (see Table 2 for details of the psychometric analyses).

Multivariate Analysis of Variance showed significant differences between the facilities with respect to staff perception of maintenance/introduction of practices, service flexibility, and acknowledgement of users' capacities (Wilks's $\lambda=0.72, \mathrm{~F}(10,330)=5.9$, $p<0.0001)$. Bonferroni's post hoc highlighted a greater perception of changes in practices among community mental health centers staff vs. general hospital psychiatric unit and residential facilities staff; and, a greater perception of service flexibility among social cooperatives staff vs. general hospital psychiatric unit and residential facilities staff. The analysis also showed a tendency for greater acknowledgement of users' capabilities among community mental health centers staff vs. social cooperatives staff $(p=0.56)$. No other significant difference between facilities was detected (Table 3).

\section{Discussion}

Interpretation of the Results

The results of this study indicated that after one year of the pandemic, most MHS staff felt they had been able to change practices and reinvent the work organization, reevaluating teamwork and recognizing capabilities to users. The study also revealed that perceptions of positive changes were greater among professionals working in the community than among those working in hospital/residential facilities.

Most participants stated that they had found some positives in the pandemic experience. This belief may reflect the high percentage of "true/completely true" responses to most items, which, in turn, could be an indirect indicator of the service resiliency. It is likely that the one-year assessment gave enough time for people to use their inherent capacities to bounce back. It should be noted that positive changes involve several aspects of MHS functioning, such as revision of therapeutic plans in light of new needs for care, 
Table 2 Confirmatory Factorial Analysis (CFA) on the 30 items of the QT-S (N = 184)

Items

*, people with severe mental disorder demonstrated good adaptive skills

Factor loadings

*, I discovered personal resources in users that I did not believe they had $\quad .72$

*, users organized themselves into peer support groups $\quad .60$

*, users showed that they were able to self-organize and find new solutions $\quad .71$

*, I realized that there were users who know how to use digital technologies better than I did $\quad .33$

*, we realized the importance of simple gestures like drinking coffee together, shaking hands, and hugging .43 each other

*, there was more sharing of responsibilities within the team

*, more centrality was given to the meetings and to dialogue with the other person .68

*, I had more time to think about my work $\quad .42$

*, we colleagues strengthened each other to face the fear $\quad 64$

*, the sense of being part of a team strengthened $\quad .83$

*, service meetings were an opportunity for group reflection on work practices 70

*, the guidelines of the Local Health Authority on how to work safely made us feel more reassured .60

*, we became more flexible toward remaining close to users

*, we reinvented our way of working in line with government mandates 54

*, we were able to make organizational/operational changes very quickly 63

*, we mediated between user demands and the procedures needed to work safely .57

*, we increased phone contact with users $\quad .31$

*, we took more better care maintaining cleanliness in the work environment .48

*, we placed more importance on family members and the close relationships of users .54

*, we learned to use digital communication technologies to work with other public institutions and the .45 third sector

*, we paid more attention to the physical health of users

*, we redefined the use of service spaces in a more rational way .61

*, we revised the users' programs according to their new needs $\quad .72$

*, I learned to use the PC and digital technologies better (e.g., video calling and conferencing platforms) $\quad .50$

*, the mental health center remained the key point of referral for people with a fragile/absent family .35 network

*, during hospitalization we guaranteed the contact of users with their families .32

*, we managed people in crisis as much as possible at home $\quad 34$

*, we informed users about the pandemic and how to reduce individual risk of infection .41

*, I found some positives in this experience 1

Cronbach's $\alpha$

$\begin{array}{lllll}.68 & .83 & .71 & .79 & -\end{array}$

*During the pandemic; Factor 1: Acknowledgement of user capabilities; factor 2: Awareness and value of teamwork; factors 3: Flexibility and ability to reinvent the service; factor 4: Maintenance and introduction of best practices; factor 5: Acknowledgement of positive aspects in the pandemic experience. The correlations among the five factors were all significant for $\mathrm{p}<.001$ (standardized solution)

greater attention to users' physical health, and increased home-based crisis management. In line with other studies $[4,15,26]$, most participants reported an increased use of digital technology. The use of videocommunication platforms not only reduced travel- related workloads but also led to devising innovative treatment packages. In particular, since the early pandemic phase, a platform for help care, entertainment and training was developed to integrate into the healthcare programs. The "Platform for Inclusion" 
Table 3 Views of mental health services staff on positive changes during the pandemic: differences between work settings

\begin{tabular}{|c|c|c|c|c|}
\hline \multirow[b]{2}{*}{ QT-S factors } & \multicolumn{3}{|l|}{ Participants' workplaces } & \multirow{2}{*}{$\begin{array}{l}\text { MANOVA } \\
\text { F }(2,172)\end{array}$} \\
\hline & $\begin{array}{l}\text { Residential facilities and general } \\
\text { hospital psychiatric unit }(\mathrm{N}=26)\end{array}$ & $\begin{array}{l}\text { Community mental } \\
\text { health centers } \\
(\mathrm{N}=89)\end{array}$ & $\begin{array}{l}\text { Social } \\
\text { cooperatives } \\
(\mathrm{N}=57)\end{array}$ & \\
\hline & mean \pm sd & mean \pm sd & mean \pm sd & \\
\hline $\begin{array}{l}\text { Acknowledgement of user } \\
\text { capabilities }\end{array}$ & $3.5 \pm 0.9$ & $3.8 \pm 0.9$ & $3.5 \pm 0.9$ & $3.57,<.03$ \\
\hline Awareness and value of teamwork & $3.8 \pm 0.7$ & $4.2 \pm 0.9$ & $4.3 \pm 1.0$ & 2.08, NS \\
\hline $\begin{array}{l}\text { Flexibility and ability to reinvent the } \\
\text { service }\end{array}$ & $4.5 \pm 0.8^{\mathrm{b}}$ & $4.8 \pm 0.9^{\mathrm{a}, \mathrm{b}}$ & $5.1 \pm 0.8^{\mathrm{a}}$ & $5.90,<.003$ \\
\hline $\begin{array}{l}\text { Maintenance and introduction of best } \\
\text { practices }\end{array}$ & $4.5 \pm 0.5^{\mathrm{b}}$ & $5.0 \pm 0.6^{\mathrm{a}}$ & $4.7 \pm 0.6^{\mathrm{a}, \mathrm{b}}$ & $6.39,<.002$ \\
\hline $\begin{array}{l}\text { Acknowledgement of positive } \\
\text { aspects in the pandemic experience }\end{array}$ & $4.3 \pm 1.4$ & $4.5 \pm 1.3$ & $4.6 \pm 1.5$ & $0.65, \mathrm{NS}$ \\
\hline
\end{tabular}

*12 missing data excluded from Multivariate Analysis of Variance (MANOVA); Bonferroni post-hoc comparisons: $\mathrm{a}>\mathrm{b}$; $\mathrm{NS}=$ non-significant $\mathrm{p}$ value

enhanced home activities, facilitated the acquisition of skills and new educational tools by the users, and reduced loneliness [6]. Effectiveness studies are needed to assess the long-term impact and feasibility of digital resources on MHS in the COVID-19 pandemic era [10].

Fifty-seven percent of the participants indicated that they had become more flexible regarding working alongside people during the pandemic, a percentage higher than that reported by D'Avanzo et al. [4] in the early COVID-19 pandemic, where $32 \%$ of MHS staff pointed out greater work flexibility. In line with previous research data [15], most professionals revalued the teamwork and relied upon colleagues' support to cope with contagion fear. Interestingly, $54.4 \%$ of participants were convinced that they discovered personal resources in users that they did not expect to find, and $35.5 \%$ acknowledged good coping skills to people with severe mental disorders. As hypothesized by some authors $[9,26]$, it might be that the reduced social pressure facilitated the adaptation of users with severe mental disorders to the pandemic. Another explanation could be that the pandemic reduced users' social opportunities within the MHS. This may have led some to revalue external social relationships that, in turn, reinforced coping skills. Regardless of the motivation, the staff acknowledgement of users' capacities is encouraging, since this can positively influence stigma in MHS [18, 25] and facilitate users' empowerment. Ad hoc studies are needed to estimate the long-term impact of the pandemic on the staff-user relationships and the recovery processes.

The study found significant differences in positive changes between facilities. Specifically, compared to residential and hospital facilities staff, professionals in community services had greater perceptions of positive changes in the practices and valued the services as more capable of adapting to users' new needs. These differences, in line with previous findings [4, 15], highlight the greater manageability of the pandemic in community MHS, which is partially related to longterm collaboration with the third sector and the user and family associations [7]. The lower perception of positive changes by the general hospital psychiatric unit and residential facilities staff could also be related to users' clinical conditions and facilities' characteristics requiring stricter rules to limit contagions [5].

Overall, the encouraging results of this study can be interpreted within the framework of Lazarus and Folkman's [17] transactional model, which postulates that the adaptation to an event is a process based on primary and secondary cognitive appraisal. Regarding the impact of COVID-19 pandemic on MHS, primary appraisal referred to what the pandemic was, as documented by the early-phase studies. Secondary appraisal concerned the emotional and problemoriented strategies to cope with the pandemic in the long-term. Internal factors, such as individual attitudes and commitment to work, and external factors, such as MHS approach and team cohesion, may have 
influenced the adaptation process. This, in turn, may have led professionals to recognize several positive changes in their work during the pandemic, despite the difficulties they encountered $[2,22]$.

\section{Strength and Limitations of the Study}

This is the first study conducted in Italy that systematically explored staff views on the positive transformations occurring in MHS during the first year of the pandemic. The multidisciplinary working group and the participatory approach facilitated the development of an instrument, which was well accepted by participants (low percentage of missing responses) and encompassed different perspectives. The fact that the QT-S is rapid to fill in and has good psychometric properties will facilitate the study replication in other settings as well as data comparison. Moreover, the fact that the QT-S items can be grouped into five higherorder dimensions makes it easier to interpret the results.

The survey was conducted in a single MHS network whose organizational model, largely adopted throughout the Friuli Venezia Giulia region [3], is strongly community-oriented. Therefore, the results of this study may not be fully generalizable to services with different patterns of care. Moreover, a total of $43.6 \%$ of eligible participants completed the questionnaire. It cannot be excluded that non-participants had a more negative perception of the impact of COVID-19 pandemic on the service. Therefore, the results may overestimate the positive changes in the MHS. In addition, the research investigated staff perceptions of positive changes and it did not explore whether such perceptions reflected real changes in the service. Nor can it be ruled out that responses were influenced by social desirability, despite the anonymity in data collection. Finally, the study examines changes from the view of staff, not considering the perspectives of users and their families. Some of these limitations will be addressed in further studies, which are currently in the planning stages.

\section{Conclusions}

This survey sought to examine the pandemic with a new approach, i.e., looking at the positive changes rather than the negative impact it produced. The study provided a snapshot of a community-oriented MHS network that looked back and gave an all-around positive rating of its performance in the first year of the COVID-19. The results of this study highlight that, in a community-oriented MHS, the pandemic also represented-and continues to represent-an opportunity to change practices and the relationships among professionals and between professionals and users. We hoped that these data will contribute to the understanding of the impact of COVID-19 on MHS and to the design of community-oriented and personcentered services in the pandemic era [10,28].

Acknowledgements The authors thank the 184 participating professionals for giving us their time.

Authors' Contributions Conceptualization: Lorenza Magliano. Methodology: Lorenza Magliano, Tommaso Bonavigo, Claudia Battiston, Alessandra Oretti, Roberta Accardo, Gabriella D'Ambrosi, Elisabetta Pascolo-Fabrici. Analysis and interpretation of the data: Gaetana Affuso, Lorenza Magliano, Tommaso Bonavigo. Drafting and revising: Lorenza Magliano, Gaetana Affuso, Tommaso Bonavigo. Funding acquisition: Lorenza Magliano. Final approval of the submitted version: all authors.

Funding The study was supported by Grants from the University of Campania "Luigi Vanvitelli", Caserta, Italy (approval no. 3.7, 09/03/2021).I

Availability of Data and Material The data that support the findings of this study are available from the corresponding author upon reasonable request, which must include a protocol and statistical analysis plan and not be in conflict with our publication plan.

\section{Declarations}

\section{Conflicts of interest None.}

Ethics Approval The study protocol was approved by the Ethics Committee of the Department of Psychology of the University of Campania "Luigi Vanvitelli" (authorization n. 1 of $2 / 2 / 2021$ ), Caserta, Italy and acknowledged by the Office of Clinical and Epidemiological Studies, SC Research and Innovation, Giuliano Isontina University Health Authority (Azienda Sanitaria Universitaria Giuliano Isontina - ASUGI), Trieste, Italy. The study was carried out in accordance with the principles of the Declaration of Helsinki.

Consent to Participate and for Publication Informed consent for participation and data publication was requested from each participant in the initial section of the online questionnaire.

Open Access This article is licensed under a Creative Commons Attribution 4.0 International License, which permits use, sharing, adaptation, distribution and reproduction in any 
medium or format, as long as you give appropriate credit to the original author(s) and the source, provide a link to the Creative Commons licence, and indicate if changes were made. The images or other third party material in this article are included in the article's Creative Commons licence, unless indicated otherwise in a credit line to the material. If material is not included in the article's Creative Commons licence and your intended use is not permitted by statutory regulation or exceeds the permitted use, you will need to obtain permission directly from the copyright holder. To view a copy of this licence, visit http://creativecommons.org/licenses/by/4.0/.

\section{References}

1. Bommersbach T, Dube L, Li L. Mental health staff perceptions of improvement opportunities around COVID-19: a mixedmethods analysis. Psychiatr Q, 1-14.92(3), 1079-1092. https:// doi.org/10.1007/s11126-021-09890-2(2021)

2. Carpiniello B, Tusconi M, Zanalda E, Di Sciascio G, Di Giannantonio M, Executive Committee of The Italian Society of Psychiatry. Psychiatry during the Covid-19 pandemic: a survey on mental health departments in Italy. BMC Psychiatr, 20(1), 593 (2020). https://doi.org/10. 1186/s12888-020-02997-z

3. Castelpietra G, Colli C, Tossut D, Furlan M, Balestrieri M, Starace F, et al. The impact of Covid-19 pandemic on community-oriented mental health services: the experience of Friuli Venezia Giulia region, Italy. Health Policy Technol. 2021;10(1):143-50. https://doi.org/10.1016/j.hlpt.2020.12. 002.

4. D'Avanzo B, Motto D, Rocca G. Mental health care in the COVID-19 era. Opinions and experiences of professionals in Italy. WARP-E Bulletin. 2020;45:10-4.

5. de Girolamo G, Cerveri G, Clerici M, Monzani E, Spinogatti F, Starace, et al. Mental Health in the Coronavirus Disease 2019 Emergency-The Italian Response. JAMA Psychiat. 2020;77(9):974-6. https://doi.org/10.1001/jamapsychiatry. 2020.1276 .

6. Dipartimento di Salute Mentale di Trieste e Gorizia Azienda Sanitaria Universitaria Integrata Giuliano Isontina. (2020). Mental Health - Basaglia's legacy 40 years later: theories, practice, service organization. Session on: COVID-19 and mental health: the impact of pandemic on users, families and services (Franco Basaglia 40 anni dopo Teorie, pratiche e organizzazione dei servizi. Sessione su: COVID-19 e salute mentale: l'impatto della pandemia su utenti, famiglie e servizi=). Workshop included in the Science in the City Festival of the EuroScience Open Forum (ESOF 2020). Trieste, September 1st, 2021. Retrieved June 27, 2021, from https://www.youtube.com/watch?v=ZxAy3NTMhg \& $\mathrm{t}=7 \mathrm{~s}$

7. Fioritti A, Cardamone G, Nicolò G, Veltro F. Stress e resilienza ai tempi della pandemia nei Dipartimenti di salute Mentale italiani (Stress and resilience during the pandemic in Italian Mental Health Departments). Nuova Rivista di Studi Psichiatrici 2021; 25. Retrieved July 7, 2021, from http://www.nuovarassegnastudipsichiatrici.it/index.php/vol ume-22/stress-resilienza-pandemia-dipartimenti-salute-men tale-italiani (2021)
8. Fontecedro E, Furlan M, Tossut D, Pascolo-Fabrici E, Balestrieri M, Salvador-Carulla L, et al. Individual health budgets in mental health: results of its implementation in the Friuli Venezia Giulia Region, Italy. Int J Environ Res Public Health. 2020;17(14):5017. https://doi.org/10.3390/ijerph17145017.

9. Gillard S, Dare C, Hardy J, Nyikavaranda P, Rowan Olive $\mathrm{R}$, Shah $\mathrm{P}$, et al. Experiences of living with mental health problems during the COVID-19 pandemic in the UK: a coproduced, participatory qualitative interview study. Soc Psychiatry Psychiatr Epidemiol. 2021;56:447-1457. https:// doi.org/10.1007/s00127-021-02051-7.

10. Goldman ML, Druss BG, Horvitz-Lennon M, Norquist GS, Kroeger Ptakowski K, Brinkley A, et al. Mental Health Policy in the Era of COVID-19. Psychiatr Serv. 2020;71(11):1158-62. https://doi.org/10.1176/appi.ps.202000219.

11. Guan I, Kirwan N, Beder M, Levy M, Law S. Adaptations and innovations to minimize service disruption for patients with severe mental illness during COVID-19: perspectives and reflections from an assertive community psychiatry program. Community Ment Health J. 2021;57(1):10-7. https://doi.org/10.1007/s10597-020-00710-8.

12. Hossain MM, Tasnim S, Sultana A, Faizah F, Mazumder H, Zou L, et al. Epidemiology of mental health problems review. Research. 2020;9:636. https://doi.org/10.12688/ f1000research.24457.1.

13. IBM Corp. Released 2012. IBM SPSS Statistics for Windows, Version 21.0. Armonk, NY: IBM Corp.

14. Il Gazzettino. February 21, 2021 - Update on Covid-19 cases. Aggregated regional data, Ministry of Health, National Health Institute. Retrieved June 22, 2021, from https://www.ilgazzettino.it/uploads/ckfile/202102/SCARIC A\%20QUI\%20IL\%20BOLLETTINO_21172640.pdf

15. Johnson S, Dalton-Locke C, Juan VS, N., Foye, U., Oram, S., Papamichail, A., et al. Impact on mental health care and on mental health service users of the COVID-19 pandemic: a mixed methods survey of UK mental health care staff. Soc Psychiatry Psychiatr Epidemiol. 2021;56(1):25-37. https:// doi.org/10.1007/s00127-020-01927-4.

16. Jöreskog KG, Sörbom D. LISREL 8: User's Reference Guide. USA: Scientific Software International; 1996.

17. Lazarus R, Folkman S. Stress, appraisal and coping. New York: Springer; 1984.

18. Magliano L, Read J, Affuso G. Predictors of staff attitudes toward Schizophrenia treatments. Psychiatr Serv. 2017; 68(12):1321. https://doi.org/10.1176/appi.ps.201700257.

19. Mezzina R. Community mental health care in Trieste and beyond: An "Open Door-No Restraint" system of care for recovery and citizenship. J Nerv Ment Dis. 2014;202(6): 440-5. https://doi.org/10.1097/NMD.0000000000000142.

20. Mezzina R. Forty years of the Law 180: the aspirations of a great reform, its successes and continuing need. Epidemiol Psychiatr Sci. 2018;27(4):336-45. https://doi.org/10.1017/ S2045796018000070.

21. Ministry of Health, National Health Institute, Report n. 41 National data synthesis. Retrieved June 22, 2021, from http://www.ministerosalute.it/imgs/C_17_monitoraggi_46_ 0_fileNazionale.pdf

22. Rapisarda F, Vallarino M, Cavallini E, Barbato A, Brousseau-Paradis C, De Benedictis L, et al. The early impact of the Covid-19 emergency on mental health workers: a survey 
in Lombardy, Italy. Int $\mathbf{J}$ Environ Res Public Health. 2020;17(22):8615. https://doi.org/10.3390/ijerph17228615.

23. Richter D, Riedel-Heller S, Zürcher SJ. Mental health problems in the general population during and after the first lockdown phase due to the SARS-Cov-2 pandemic: rapid review of multi-wave studies. Epidemiol Psychiatr Sci. 2021;30: e27. https://doi.org/10.1017/S2045796021000160.

24. Saponaro A, Ferri M, Ventura C, Carozza MP, Chiesa S, Fioritti A, et al. Monitoraggio dell'impatto della pandemia COVID-19 sui Servizi di salute Mentale e Dipendenze Patologiche (Monitoring of the impact of COVID-19 pandemic on Mental Health and Pathological Addictions Services). Sestante. 2020;10:13-9.

25. Schulze B. Stigma and mental health professionals: a review of the evidence on an intricate relationship. Int Rev Psychiatry. 2007;19(2):137-55. https://doi.org/10.1080/0954026070127 8929.

26. Sheridan Rains L, Johnson S, Barnett P, Steare T, Needle JJ, Carr S, et al. Early impacts of the COVID-19 pandemic on mental health care and on people with mental health conditions: framework synthesis of international experiences and responses. Soc Psychiatry Psychiatr Epidemiol. 2021;56(1):13-24. https://doi.org/10.1007/s00127-02001924-7.
27. Webber M, Treacy S, Carr S, Clark M, Parker G. The effectiveness of personal budgets for people with mental health problems: a systematic review. J Mental Health Engl. 2014;23(3):146-55. https://doi.org/10.3109/09638237. 2014.910642.

28. World Health Organization (WHO). Guidance and technical packages on community mental health services: promoting person-centered and rights-based approaches. Retrieved June 28, 2021, from https://www.who.int/publications/i/ item/9789240025769

29. World Health Organization (WHO). The World health report: 2001. Mental health: new understanding, new hope. Retrieved June 28, 2021, from https://www.who.int/whr/ 2001/en/whr01_en.pdf

30. Zhang Y, Lange KW. Coronavirus disease 2019 (COVID-19) and global mental health. Global Health J. 2021;5(1):31-6. https://doi.org/10.1016/j.glohj.2021.02.004.

Publisher's Note Springer Nature remains neutral with regard to jurisdictional claims in published maps and institutional affiliations. 